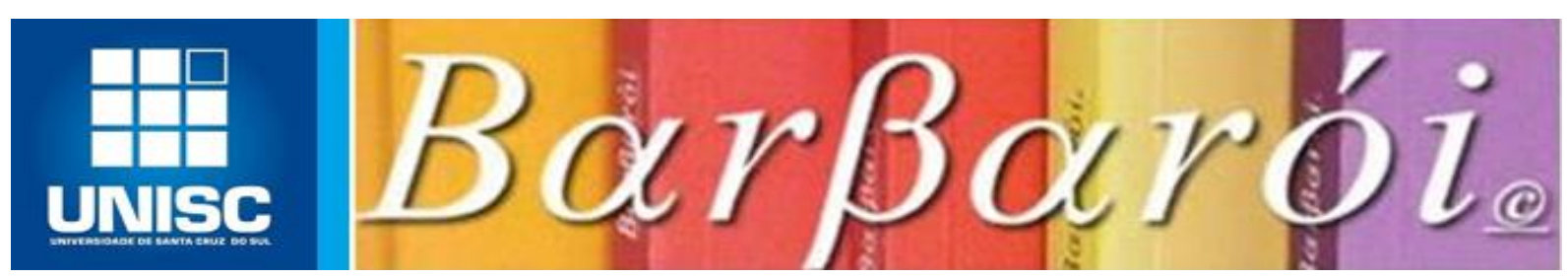

\title{
PROCESSO DE INCLUSÃO DO ADULTO COM SÍNDROME DE ASPERGER NO ENSINO SUPERIOR
}

\section{DOI: http://dx.doi.org/10.17058/barbaroi.v0i49.6355}

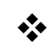 \\ Angélica da Costa \\ Universidade do Vale dos Rios dos Sinos - UNISINOS - Brasil \\ Angela Helena Marin \\ Universidade do Vale dos Rios dos Sinos - UNISINOS - Brasil
}

\section{Resumo}

O presente artigo tem como temática a inclusão de alunos adultos com Síndrome de Asperger (SA) no ensino superior. Como objetivo, buscou compreender o processo de inclusão de adultos com SA em uma instituição de ensino superior (IES) a partir da perspectiva do aluno e sua família, bem como dos professores, assistente social e psicóloga da IES. Caracterizou-se o contexto familiar e socioeconômico desses universitários e a relação deles e de sua família com os profissionais da IES. Realizou-se um estudo de caráter exploratório e transversal, com delineamento de estudos de casos múltiplos. Participaram dois adultos com SA, do sexo masculino, com idade entre 18 e 20 anos, matriculados em uma IES privada, localizada na região metropolitana de Porto Alegre (RS), bem como seus pais, professores, assistente social e psicóloga da IES. Como instrumento de coleta de dados utilizaram-se entrevistas semiestruturadas. A análise de conteúdo qualitativa, a partir do método de proposições teóricas, revelou que a perspectiva de conclusão do ensino superior tem significados diferentes para as famílias investigadas e que sua relação com a IES, embora exista, precisa ser incentivada. Também se constatou a necessidade de qualificação dos professores referente à inclusão. Acredita-se que este estudo possibilitou um melhor entendimento sobre a inclusão do adulto com SA através do olhar dos envolvidos neste processo.

Palavras-chave: Inclusão. Síndrome de Asperger. Relação família-universidade.

\section{Introdução:}

A inclusão de pessoas com deficiência física ou intelectual atualmente é um imperativo e Instituições de Ensino Superior (IES), famílias, sociedade e Estado devem estar atentos aos direitos que lhe são assegurados para lhes oferecer um ambiente sadio e adaptado às suas necessidades. Nesse sentido, este estudo teve como objetivo geral compreender o processo de inclusão de alunos com Síndrome de Asperger (SA) no ensino superior por meio da perspectiva do próprio aluno, sua família e dos profissionais da IES que o acompanham, como os seus professores, assistente social e psicóloga. Como objetivos específicos pretendese caracterizar o contexto familiar e socioeconômico dos universitários e a relação deles e de 
suas famílias com a IES e seus profissionais. Sabe-se que de acordo com a última revisão do Manual Diagnóstico e Estatístico de Desordens Mentais (DSM V), da Associação Psiquiátrica Americana (APA, 2013), a Síndrome de Asperger está alocada na categoria Transtornos do Espectro Autista (TEA), mas optou-se por continuar usando esta nomenclatura, visto que os participantes foram assim diagnosticados ainda na infância, conforme atestado médico apresentado na IES. Espera-se com este estudo contribuir para o melhor entendimento do processo da inclusão universitária, colaborando para a consolidação do trabalho de profissionais que visam à integração entre famílias e IES.

\section{Acessibilidade e inclusão nas IES:}

A Política Nacional de Educação Especial foi publicada no Brasil em 1994, tornando o acesso de estudantes com deficiência ao ensino regular condicionado aos que "[...] possuem condições de acompanhar e desenvolver as atividades curriculares programadas do ensino comum, no mesmo ritmo que os alunos ditos normais" (BRASIL, 1994, p. 19), atribuindo-se às características físicas, intelectuais ou sensoriais de estudantes um caráter incapacitante, resultando em impedimento para sua inclusão social e educacional. Em concordância, a Lei de Diretrizes e Bases da Educação Nacional (BRASIL, 1996) e a Resolução número 02 do Conselho Nacional de Educação (CNE, 2001), mesmo que se orientasse a matrícula de estudantes da educação especial nas escolas da rede regular de ensino, mantinha-se a possibilidade do atendimento educacional especializado substitutivo à escolarização. Felizmente, houve avanços e a Política Nacional de Educação Especial na Perspectiva da Educação Inclusiva (BRASIL, 2008) passou a definir a Educação Especial como uma modalidade transversal a todos os níveis e etapas de ensino, tendo como função disponibilizar recursos e serviços de acessibilidade e atendimento educacional especializado, complementar a formação dos estudantes com deficiência, transtornos globais do desenvolvimento e altas habilidades/superdotação. Essa política também preconiza que na educação superior, a educação especial se efetive por meio de ações que promovam o acesso, a permanência e a participação dos estudantes com algum tipo de deficiência.

No artigo $2^{\circ}$ do Estatuto da Pessoa com Deficiência (BRASIL, 2015) consta que se consideram pessoas com deficiência aquelas que têm impedimentos de natureza física, mental, intelectual ou sensorial em longo prazo, os quais podem obstruir sua participação plena e efetiva na sociedade em igualdade de condições com as demais pessoas. A partir da Declaração de Montreal sobre Deficiência Intelectual, aprovada em 2004 pela Organização 
Mundial de Saúde (OMS, 2004), em conjunto com a Organização Pan-Americana da Saúde (Opas), a terminologia "deficiência mental" foi substituída por "deficiência intelectual”, que pode ser definida como o funcionamento intelectual significativamente inferior à média, com manifestação no período de desenvolvimento cognitivo antes dos 18 anos e limitações associadas a duas ou mais áreas de habilidades adaptativas, tais como: a) comunicação; b) cuidado pessoal; c) habilidades sociais; d) utilização dos recursos da comunidade; e) saúde e segurança; f) habilidades acadêmicas; g) lazer e h) trabalho (BRASIL, 2003).

Destaca-se que a categoria Síndrome de Asperger, foco deste estudo, foi incluída no Censo da Educação Superior de 2011 como deficiência intelectual. Contudo, no Manual Diagnóstico e Estatístico de Desordens Mentais - DSM-V (APA, 2013), a Síndrome de Asperger está alocada na categoria Transtornos do Espectro Autista (TEA) e traz uma tríade diagnóstica baseada na presença dos seguintes critérios: a) déficits de comunicação/interação social; b) presença de um padrão repetitivo e restrito de atividades, interesses e comportamentos; e c) presença dos sintomas desde o início da infância, que podem não se manifestar completamente até que as demandas sociais excedam o limite de suas capacidades. Já o Código Internacional de Doenças (CID 10), da Organização Mundial de Saúde (OMS, 2000), conceitua a Síndrome de Asperger como um "transtorno de validade nosológica incerta, caracterizado por uma alteração qualitativa das interações sociais recíprocas, semelhante à observada no autismo, com um repertório de interesses e atividades restrito, estereotipado e repetitivo". Ele se diferencia do autismo essencialmente pelo fato de que não é acompanhado de um retardo ou deficiência de linguagem ou do desenvolvimento cognitivo. As anomalias persistem frequentemente na adolescência e pode haver episódios psicóticos no início da idade adulta.

Participaram do último Censo da Educação Superior, publicado no ano de 2011, 2.365 IES. Os dados revelaram que $88 \%$ delas são privadas e $12 \%$ públicas, sendo $4,7 \%$ estaduais, 4,3\% federais e 3,0\% municipais (INEP, 2011). Quanto ao número de matrículas, registrou-se um total de 6.739 .689 nos cursos de graduação e um crescimento de 357,86\% em matrículas de alunos com deficiência (5.078 em 2003 e 23.250 em 2011). Ressalta-se que $72 \%$ das matrículas (1810 matrículas) de estudantes com deficiência estão em IES privadas. Especificamente quanto à matrícula de alunos com deficiência intelectual, 477 foram registradas, sendo 167 delas na esfera pública e 310 na privada. Com Síndrome de Asperger, há apenas 30 matrículas e quatro delas no estado do Rio Grande do Sul, sendo três na esfera privada e uma na pública (INEP, 2011). 
Considerando o universo de pessoas com deficiência intelectual que poderiam estar inseridas no ensino superior e a quantidade de matrículas nas demais categorias de deficiência, esse número pode ser considerado inexpressivo, ainda mais se for considerado que, em 2013, 6,2\% da população brasileira apresentava algum tipo de deficiência, sendo que destes, 0,8\% possuíam algum tipo de deficiência intelectual (IBGE, 2013).

Para Dantas (2012), a inclusão escolar evidenciada na educação infantil e na educação fundamental tende a ser interrompida quando as pessoas com deficiência intelectual chegam à fase adulta, havendo, muitas vezes, um retorno às instituições especializadas ou a permanência forçada em casa. Contudo, como visto, o direito à educação superior da pessoa com deficiência está assegurado e fundamentado nos princípios e diretrizes da Convenção sobre os Direitos das Pessoas com Deficiência (ONU 2006) e nos Decretos n ${ }^{\circ}$ 186/2008, 6.949/2009, 5.296/2004, 5.626/2005 e 7.611/2011.

\section{Famílias com filhos com Síndrome de Asperger (SA):}

A família desempenha um papel fundamental na construção da identidade, pois é nela que se formam os primeiros laços, vínculos e relações afetivas. Ela é o ambiente no qual se estabelecem as relações sociais, constituindo o equilíbrio emocional, social e educacional, portanto, considera-se "a família como um sistema aberto constituído por muitas unidades ligadas no conjunto por regras de comportamento e funções dinâmicas, em constante interação entre elas e em intercâmbio com o exterior" (ANDOLFI, 1981, p. 20).

A dinâmica de cada família é própria e pode ser afetada tanto pelo desenvolvimento de seu ciclo vital como pelas políticas econômicas e sociais (CARTER; MCGOLDRICK, 1995; FERRARI; KALOUSTIAN, 2004). Promover suporte social e emocional aos seus membros e educar os filhos, auxiliando em suas crises de desenvolvimento, é função primordial da família (GOMES, 2013). A partir disso, aborda-se o funcionamento de famílias que possuem um membro com SA.

Dificuldades vivenciadas por um dos membros podem mobilizar a todos na família e requererem desse sistema flexibilidade e capacidade de se reestruturar para continuar atendendo às suas necessidades (ZARANZA, 2008). Fávero (2005) identificou reações familiares diversas quando um dos filhos tem deficiência, dentre as quais se destacaram a estranheza provocada pelo comportamento associado à deficiência e a dificuldade dos pais para exercer outros papéis, como o conjugal e até mesmo o parental com os demais filhos, assim como de se dedicarem à carreira profissional ou cuidar de si mesmos. Segundo o autor, 
a flexibilidade com que a família irá lidar com a situação dependerá das experiências prévias, aprendizagens e personalidade dos seus membros.

As famílias com filhos com deficiência precisam dedicar-lhes tempo e atenção adicional, demandando a construção de estratégias para se adaptar a essa nova realidade de modo que correspondam às necessidades dos demais membros, pois, conforme Vital (2003, p. 67) "a interpretação dada pelos pais ao problema, que determina a natureza da relação". Diante desta realidade, as relações familiares tanto podem se fortalecer como se desintegrar. Enquanto algumas famílias são capazes de serem bem-sucedidas ao proceder à adaptação, outras se encontram menos preparadas para aceitar o desafio que um membro deficiente representa (NIELSEN, 1999).

Especificamente quanto às famílias com filhos com SA, Alves (2009, p. 14) pontuou que "[...] quando ainda não é claro o diagnóstico clínico de Síndrome de Asperger, a maioria dos pais percebe que há algo de estranho com o filho, mas não sabe a razão". Pode ser comum os pais se questionarem sobre suas capacidades e atuação com outros filhos ou sobre algo que ocorreu com êxito com outros pais e para eles não. Para Borreguero (2006), essa etapa é complexa, pois suscita sentimentos de confusão, ansiedade, frustração e, especialmente, culpa e fracasso frente à inexistência de justificativas relativas às contradições observadas no comportamento do filho com SA. Mesmo após percorrerem diversos caminhos em busca de um diagnóstico, os pais ainda podem se deparar com a dificuldade em aceitar a deficiência e a necessidade de adequar à realidade imposta pela síndrome com o meio em que vivem (ATTWOOD, 2006).

Nesse sentido, a elaboração de uma avaliação detalhada quanto ao nível de desenvolvimento, padrão de dificuldades e limitações, torna-se importante levando em conta o que preocupa os pais de um filho com SA (GOMES, 2013), sendo fundamental o apoio da família (BORREGUERO, 2006). Inclusive, a experiência clínica mostra que a baixa aderência ao tratamento está associada à dificuldade de aceitação e relação com a própria família, pois um dos seus sintomas é a dificuldade para se relacionar, abordado como déficit na interação recíproca, dificuldade em criar o vínculo afetivo e a distinta percepção do mundo social (BORREGUERO, 2006).

Com o transcorrer do desenvolvimento e a iniciação da vida adulta, os pais têm a responsabilidade de ajustar as suas relações e enfrentar com os filhos com SA preocupações sobre habitação, dinheiro e oportunidades de socialização, bem como incentivar a interação com instituições que disponibilizam serviços de acompanhamento psicológico ou psiquiátrico, se necessário, além de lidarem com os interesses do filho no que diz respeito a namoro, 
matrimônio e a escolha por terem filhos. Adultos com SA, embora apresentem dificuldades nas interações sociais, podem ter uma vida social sem restrições. O Estudo de Moore (2005) indicou que quando comparadas a outras formas de autismo, crianças com SA eram mais aptas a crescer e serem adultos independentes em termos de emprego, casamento e família. Para o autor, muitos dos estudantes com SA são capazes de completar com sucesso a faculdade e assumir uma profissão relacionada à sua área de interesse exercendo-a com competência.

Contudo, as pessoas com SA costumam ser identificadas como diferentes ou excêntricas, podendo ter problemas com a empatia e a modulação da interação social. Isso porque elas tendem a ter mais dificuldade frente à necessidade de tomada de decisões nas interações sociais, devido à rigidez de estilo e perspectiva diferente que tem do mundo, pois seus padrões de pensamento são técnicos e lógicos, seus interesses são específicos e possuem dificuldade para entender a linguagem e as emoções alheias (WILLIAMS; WRIGHT, 2008). De acordo com Dantas e Alchieri (2012), as deficiências de comunicação social interferem na integração com o grupo de iguais, aumentando conforme as expectativas e as exigências da idade.

Frente ao exposto, o objetivo geral do presente estudo foi compreender o processo de inclusão de alunos com SA no ensino superior por meio da perspectiva do próprio aluno, sua família e profissionais da instituição que o acompanham, como os seus professores, o assistente social e o psicólogo. Já como objetivos específicos buscou-se caracterizar o contexto familiar e socioeconômico desses universitários, a relação de sua família com a instituição e a relação entre eles e os profissionais da instituição.

\section{Metodologia:}

\section{Participantes e delineamento:}

Participaram deste estudo dois adultos do sexo masculino, com idades entre 18 e 20 anos, com diagnóstico de SA, matriculados em uma IES privada, localizada na região metropolitana de Porto Alegre-RS, bem como seus pais, professores, assistente social e psicóloga da instituição. Trata-se de uma pesquisa qualitativa, de caráter exploratório e transversal, com delineamento de estudos de casos múltiplos (YIN, 2005). 


\section{Instrumentos:}

Como instrumentos de levantamento de dados foram utilizados: - Entrevista semiestruturada com o aluno com SA: apresentava quatorze tópicos para discussão que se voltavam sobre a percepção acerca do seu desenvolvimento no âmbito universitário e relacionamento entre sua família e a IES; - Entrevista semiestruturada com a/o mãe/pai do aluno com SA: possuía onze tópicos para discussão que investigavam sobre o entendimento que as mães ou os pais têm em relação ao desenvolvimento de seu filho no âmbito universitário e o relacionamento entre a família e a IES; - Entrevista semiestruturada com os professores do aluno com SA: reunia doze tópicos para discussão que abordavam sobre a atuação dos professores com um aluno adulto com SA, a avaliação de sua inclusão universitária e a sua concepção a respeito do seu rendimento acadêmico; - Entrevista semiestruturada com os profissionais da IES que acompanhavam o aluno: contemplava seis tópicos para discussão que refletiam sobre a atuação dos profissionais que atendiam o aluno com SA e como avaliam a inclusão universitária e social desse aluno.

\section{Procedimentos éticos e de coleta de dados:}

Foi solicitado à Gerência de Atenção ao Aluno da referida IES a autorização para a realização da coleta de dados no local. Após o aceite, foi assinada a Carta de Anuência para a realização da pesquisa e o projeto foi submetido e aprovado pelo Comitê de Ética da IES, de acordo com a resolução 466/12, protocolado sob o número 13/160.

Os alunos com SA e seus pais, bem como professores, assistente social e psicóloga da IES foram convidados para um encontro para apresentação da proposta do projeto de pesquisa. Os que aceitaram fazer parte do estudo assinaram o Termo de Consentimento Livre Esclarecido. Após, foram agendadas as entrevistas com cada participante, que foram realizadas individualmente e gravadas em áudio para posterior transcrição.

\section{Procedimentos de análise de dados:}

Foi utilizada a análise dos dados proposta por Yin (2005), que consiste no exame, categorização e classificação das evidências conforme os objetivos do estudo. Sendo assim, inicialmente, as categorias de análise foram definidas considerando as relações entre o aluno com SA, sua família, seus professores e os profissionais da IES que o acompanhavam. O segundo passo consistiu em utilizar a técnica de construção da explanação, que tem por objetivo analisar os dados de cada caso. Por fim, foi feito um comparativo entre os casos 
analisados, destacando suas semelhanças e particularidades a fim de analisar o processo de inclusão de adultos com SA no ensino superior.

\section{Resultados e discussão:}

Após o levantamento dos dados, cada caso foi construído individualmente e organizado em três eixos temáticos definidos a posteriore, com base nos relatos: 1) a descoberta da SA: família e instituição de ensino superior, 2) a tríade: família, IES e inclusão, 3) desafios sociais e acadêmicos. Dois juízes independentes classificaram os relatos dentre os eixos apresentados utilizando o critério de consenso. Os nomes utilizados na apresentação dos casos são fictícios.

\section{Caso 1 - Max:}

O participante Max tinha 19 anos e foi diagnosticado com SA aos 5 anos, desde quando fazia terapia. Residia com a família: seus pais, que possuíam profissões do grupo 1 da Classificação Brasileira de Ocupações (BRASIL, 2002), e seu irmão que era estudante universitário. Max frequentou escola privada do ensino infantil ao ensino médio. Neste período teve avaliações com questões breves para sua melhor compreensão e atividades avaliativas realizadas em casa. Ingressou no ensino superior com 17 anos. Identificou-se como aluno com SA na inscrição do vestibular e realizou a prova em sala individual acompanhado por uma tutora. Na entrevista, Max relatou "foi o que me fez perceber que eu era um candidato diferencial".

\section{A Descoberta da SA: família e IES:}

A família descobriu que Max tinha SA nos seus primeiros anos de vida: "Com cinco anos tivemos o diagnóstico e logo começamos com os tratamentos possíveis para que ele tivesse uma vida normal.” (pai). Conforme Dantas e Alchieri (2012), a Síndrome de Aspeger pode ser diagnosticada quando as habilidades sociais, o desenvolvimento da comunicação e da linguagem não se desenvolvem de maneira adequada. No primeiro momento os pais ficaram abalados com a notícia e não sabiam como contar para o restante da família: "Paralisamos em frente ao médico! Tantos pensamentos passaram por minha cabeça: como contar pro irmão dele e pros avós” (mãe).

Com o passar do tempo buscaram informações sobre a SA e perceberam que Max era inteligente, com capacidade de crescer e ser um homem responsável: "Quando começamos o 
acompanhamento e vimos as possibilidades que nosso filho tinha, ficamos mais tranquilos $e$ focamos no tratamento" (pai). As famílias são por vezes vulneráveis e por outras extremamente fortes, como observa Powell e Ogle (1991), muitas vezes a situação difícil não produz efeitos negativos, ao contrário, pode tornar-se numa experiência enriquecedora.

A professora de Max destacou o desconhecimento sobre as particularidades e as estratégias que poderiam ser utilizadas no trabalho pedagógico com alunos com SA. "Não me sinto preparada! Não faz parte da minha realidade essas diferenças e eu não sei qual o limite da justiça e da bondade! Isso é difícil pra mim. Estou protegendo o aluno? Não sei!". Conforme ela, os professores universitários estão despreparados para lidar com a presença de alunos com qualquer deficiência em sala de aula: "Alguns colegas entendem que não é necessária adaptação no material didático, que são os alunos que devem se adaptar”. O fato de o professor considerar que o programa de sua disciplina deve ser seguido sem alteração pode atrapalhar o atendimento das necessidades educacionais especiais (NEE) dos alunos. "Os professores devem considerar que não existe uma só maneira de ministrar e avaliar o processo de aprendizagem, buscando formas de diversificar o seu programa" (RODRIGUES, 2004, p. 3).

Quanto ao processo de aprendizado do aluno, a professora entendia que: “A responsabilidade de aprendizagem é do aluno. O professor tem um papel importante, mas a responsabilidade é dele”. Bzuneck (2001) ressalta a importância de que se avalie o processo de aprendizagem como um todo e que o professor seja considerado como aquele que conduz os alunos a perceberem seus erros e fracassos como uma oportunidade de construção do conhecimento e não como resultante da falta de capacidade de aprendizado.

A assistente social atendeu Max pela primeira vez através da Ouvidoria: "Ele veio formalizar a reclamação da coordenação de curso que não aceitou seu atestado da SA". No atendimento, Max se mostrou ofendido e inflexível com a situação apresentada, exigindo uma retratação por parte da coordenação, conforme relata a assistente social: "Max estava inconformado! Até usou de palavras ofensivas. Alegou falta de compreensão por parte da coordenação”. Em outro momento, Max entrou em contato solicitando atendimento com a assistente social para conversar sobre suas necessidades: "Ele quis conversar sobre a SA. Max pediu que um psicólogo da instituição o atendesse para ajudar com a questão dos estudos. Ele queria um atendimento especial!"”.

A psicóloga atendeu Max pela primeira vez devido a uma demanda da coordenação de curso. A partir deste momento houve outros atendimentos e um acompanhamento na resolução da situação referente ao conflito, além de contato com os professores, conforme 
relatado pela psicóloga: "Oferecemos o espaço de atendimento ao aluno, a família e o diálogo com os docentes, na busca por resolução dos problemas apresentados”.

$\mathrm{O}$ atendimento educacional especializado é um dos pilares da educação inclusiva. $\mathrm{O}$ entendimento da Política Nacional de Educação Especial na Perspectiva da Educação Inclusiva é que ele constitui:

\begin{abstract}
Uma ação do sistema de ensino no sentido de acolher a diversidade ao longo do processo educativo, constituindo-se em um serviço disponibilizado pela escola/IES para oferecer o suporte necessário às necessidades educacionais especiais dos alunos, favorecendo seu acesso ao conhecimento. (BRASIL, 2006, p. 15).
\end{abstract}

\title{
A Tríade: família, instituição de ensino superior e inclusão:
}

O aluno Max considerava sua relação familiar excelente, pois eram unidos, faziam atividades juntos, conversavam sobre os assuntos acadêmicos: "Minha família está sempre por dentro do que acontece comigo na Universidade e acho isso muito importante: saber que posso contar com eles”. De igual forma, para os pais de Max a participação da família no processo de inclusão no ensino superior era muito significativa: "Nós sempre temos que estar presentes para o nosso filho e apoiando nos estudos" (pai). Eles acompanhavam o filho, em atividades extraclasses e se colocavam à disposição da IES quando necessário para que o trabalho em conjunto com a família trouxesse mais segurança para ambos: "A psicóloga e a assistente social conversaram conosco para buscar solução” (mãe).

Entende-se que a família é um sistema que exerce um papel preponderante na promoção dos direitos humanos e na inclusão social das pessoas com deficiência. Para Dessen e Lewis (1998), o desenvolvimento das pessoas está associado ao desenvolvimento de suas famílias, tendo em vista a qualidade das interações e relações que caracterizam o contexto familiar.

A professora também percebia que a família de Max era engajada em sua vida acadêmica e encontrava os pais de Max em atividades extraclasse: "Eles poderiam estar fazendo outra coisa, mas estavam lá acompanhando ele. Os únicos pais de aluno presentes no evento”. Weiss (2004, p. 26) afirmava que a “[...] aprendizagem é um processo de construção

que se dá na interação permanente do sujeito com o meio que o cerca, meio esse expresso inicialmente pela família, depois pelo acréscimo da escola, ambos permeados pela sociedade em que estão". Assim, entende-se que pais e IES, juntos, podem auxiliar o sujeito a superar sua dificuldade de aprendizagem, que continua e continuará se fazendo presente no ensino superior. 
Para a psicóloga, a participação da família nas questões relativas à universidade era importante para que o aluno se sinta apoiado em suas escolhas e influencia no processo de inclusão no ensino superior: "A forma como a família inclui este filho na vida em sociedade será a mesma forma como o enxergará na universidade”. A assistente social concordava com a fala da colega no que se refere à influência familiar no processo de inclusão, pois com o apoio e a motivação recebidos em casa o aluno sentia-se à vontade para fazer escolhas e buscar ajuda quando necessário: "Sem o apoio da família não há motivação para seguir em frente e concluir a graduação”.

A instituição entrou em contato com a família com o objetivo de dar suporte ao bom andamento da inclusão do aluno: "No sentido de escutar a família acerca da situação ocorrida, de conhecer e compreender a família deste aluno, bem como construir uma aliança de trabalho entre universidade, aluno e família” (psicóloga). Em consonância, a assistente social afirmou: "Achamos necessário e oportuno o encontro com a família para esclarecer possíveis dúvidas quanto ao curso escolhido e os recursos disponíveis para auxiliar Max no processo de inclusão”. A fala das profissionais vem ao encontro do que referem Barbirato e Dias (2009) de que o meio se torna fundamental para ensinar todos os envolvidos a conviver com o transtorno.

Os pais de Max perceberam uma mudança depois que ele foi atendido pela assistente social e a psicóloga da IES, pontuando que o filho ficou mais tranquilo em relação aos estudos e escolhas, e sabia onde buscar o serviço quando precisasse: "Nós já entramos em contato e consideramos importante esse trabalho, pois ajudaram muito meu filho a se tranquilizar em relação aos estudos" (pai).

Max entendia que seu processo de inclusão no ensino superior vinha sendo de acordo com o esperado por ele e sua família. Acreditava que os motivos do seu progresso eram a receptividade da instituição e os atendimentos realizados com a psicóloga e a assistente social da IES: "A equipe que me acompanha na universidade tem uma grande importância, pois eles ajudam e apoiam os alunos na medida em que os deixam mais confortáveis”. Para Max a conclusão do ensino superior era necessária para uma boa colocação no mercado de trabalho: "É complicado de conseguir um bom emprego sem ter uma formação acadêmica. O mundo tem um preconceito com indivíduos sem diploma universitário”. O processo de inclusão de Max no ensino superior é valorizado pelos pais devido a sua dedicação e seriedade nos estudos. Entendiam que a inclusão estava implicada no apoio que recebia em casa e no quanto a família valorizava sua escolha de cursar a universidade com o objetivo de se colocar no 
mercado de trabalho: "O maior aspecto positivo é que ele terá chances de conseguir um emprego apenas pelo fato de ter um diploma universitário” (pai).

Embora se reconhecesse a presença da família estimulando e incentivando a vida acadêmica do filho Max, a psicóloga destacava que quando esta participação se excede, tornando-se cobranças, elas podem atrapalhar ao invés de ajudar o aluno: "Esta família tem uma dinâmica de pensar no futuro profissional do filho e este se sente cobrado em corresponder. Pode não ser positivo para o aluno, aumentando a ansiedade e diminuindo as possibilidades de um crescimento saudável, mesmo que em tempo mais lento”. A assistente social concordava ao apontar que a família colocava muitas expectativas no filho e preocupavam-se com sua colocação no mercado de trabalho: "Deixaram claro o investimento que faziam nele. Ele tem uma preocupação excessiva em não decepcionar”.

O comportamento desta família, relatado pela psicóloga e pela assistente social da IES, pode trazer prejuízos para o aluno, inclusive comprometendo suas habilidades de interação social, pois parece estimular a competitividade. Os laços afetivos que se formam entre os membros do grupo familiar, quando positivos, favorecem o ajustamento do indivíduo aos diferentes ambientes de que participa. Quando negativos, podem dificultar o desenvolvimento, gerando problemas de ajustamento e dificuldades de interação social. (DESSEN; POLONIA, 2007). Zago (2000, p. 20-21) também afirma que:

\footnotetext{
A família, por intermédio de suas ações materiais e simbólicas, tem um papel importante na vida escolar dos filhos, e este não pode ser desconsiderado. Trata-se de uma influência que resulta de ações muitas vezes sutis, nem sempre conscientes e intencionalmente dirigidas.
}

A transformação do sonho de realizar e concluir o Ensino Superior para a pessoa com deficiência intelectual significa uma revisão de conceitos e de posturas e isso, como diz Padilha (2004), não é possível através de atitudes isoladas ou individuais.

\section{Desafios Sociais e Acadêmicos:}

Max escolheu o curso atual por gostar do seu escopo. Houve apoio dos pais, que conversaram com a coordenação do curso: "Porque é um curso mais simples do que os outros. Por eu ter Asperger, possuo uma dificuldade em entender assuntos complexos. É um curso que se alinha ao meu perfil". As dificuldades acadêmicas ou pessoais encontradas por Max eram discutidas em família: "Juntos buscamos a melhor solução, sempre prezando pela autonomia de Max e se necessário buscamos uma orientação na universidade junto à equipe especializada” (mãe). Dificuldades vivenciadas por um filho podem mobilizar todos os 
membros da família e requererem desse sistema flexibilidade e capacidade de se reestruturar para continuar atendendo às suas necessidades. (ZARANZA, 2008).

Os pais também relataram: "Percebemos que ele tem dificuldade com a linguagem, comunicação e na compreensão dos assuntos que têm que ser abordados em algumas tarefas" (mãe). Então, eles buscam elucidar as informações de forma que o filho entenda e consiga realizar o solicitado. Para eles, Max tinha um desempenho melhor quando não é exposto a pergunta e resposta direta: "Max fica nervoso quando questionado em público. Quando tem que responder diretamente e rapidamente" (pai). A professora também identificava em Max a dificuldade de falar em público: "Fica nervoso quando tem que se posicionar, defender um ponto de vista e ansioso em saber se o que está sendo feito é como eu espero". De acordo com a professora, por vezes, Max se calava perante a turma: "Ele se trava em alguns assuntos diante dos colegas. Quer ser aceito e não fala algo que poderia ser importante. Deixa de falar por medo de risos e gozação. Não quer aparecer”. Segundo Rodrigues (2012, p. 30):

Os alunos com Síndrome de Asperger têm em geral boa capacidade linguística, vocabulário extenso e capacidade de utilizar estruturas gramaticais complexas. Contudo, tem dificuldade de comunicação efetiva especialmente na utilização social da linguagem e na capacidade de transmitir e compreender o significado.

A professora entendia que Max apresentava resistência em sair da rotina, por isso quando foi apresentado o cronograma de atividades, o aluno opinou sobre as temáticas das atividades, enquanto o restante da turma não questionou: "Achei oportuna a colocação dele. Acho que foi bom porque quando um aluno recebe o plano de aula ele tem que entender o que ele vai ver na disciplina”. O acontecido nos remete a mais um sintoma da SA, que é a adesão a rotinas e a resistência às mudanças (AMORIM \& ASSUNÇÃO JR, 2012). De acordo com Attwood (2008), as pessoas com SA podem ficar muito ansiosas quando ocorre alguma mudança em sua rotina. Saber o que será feito durante a aula diminui a ansiedade e, assim, ele poderá se dedicar e concentrar nas tarefas solicitadas.

Quanto à socialização com os demais alunos, a professora referiu que acontecia de forma harmoniosa: "Ele faz o estereótipo do nerd e os outros não são nerdes. Os gostos musicais são diferentes, mas a interação dele com os outros está tranquila!’. A socialização é parte importante do desenvolvimento humano. Para Attwood (2009):

Os 'aspies' têm de aprender a fazer amigos, a arte da conversação e muitas outras ferramentas de socialização. Se esse processo arrancar bastante cedo é possível que aprendam com muito êxito. Os 'aspies' compreendem a linguagem dos computadores, da música, da matemática, mas os níveis de linguagem subjetiva sãolhes completamente estranhos. 
A experiência de ter na sala de aula um aluno com SA, do ponto de vista da professora, era enriquecedora. O aluno é aplicado, inteligente e apresenta potencial: "Não vi dificuldade do Max em poder se inserir. Não precisei dar uma atenção especial. Ele está fazendo muito bem, além do que eu imaginava! O Max é meu primeiro aluno com deficiência intelectual. Estou muito satisfeita com o trabalho realizado!".

A assistente social entendia que a socialização de Max podia estar afetada pelos sintomas da SA, mas referiu que nos atendimentos realizados, o aluno nunca trouxe nenhuma situação adversa com os colegas: "Ele tem uma fala meio robótica, usa palavras difíceis para conversar, é sempre formal. Isso pode afastar um pouco os outros, pois ele tem um entendimento que deve ser tratado diferente, de um modo especial, preferencial". Segundo Piaulino (2008), o discurso de uma pessoa com SA ocorre sem modulação, de forma monótona e com precisão na dicção de cada sílaba. Há problemas para se comunicar e, consequentemente, se relacionar com os outros, o que corrobora com o observado pelas profissionais. Por outro lado, Attwood (2009) ressalta as potencialidades das pessoas com SA, que se destacam em variados campos científicos e tecnológicos. Elas podem ter grande sucesso nas carreiras que escolhem, potencializando as suas qualidades de obstinação, memória confiabilidade e dedicação, no entanto é essencial que o ambiente de trabalho que o rodeia compreenda às suas características.

\section{Caso 2 - Adam:}

O participante Adam tinha 20 anos e foi diagnosticado com SA aos 10. Ele residia com os pais, que possuíam profissões do Grupo 8 e 9, conforme a Classificação Brasileira de Ocupações (2002), e um irmão mais velho, que era estudante universitário e trabalhador do grupo 8 do mesmo sistema de classificação. Adam sempre estudou em escolas públicas e não tinha material adaptado para suas necessidades em nenhum momento da vida escolar.

Ingressou no ensino superior em 2012, com 18 anos, mas desistiu e voltou a estudar em 2013 em outro curso. Adam não se identificou como aluno com SA no momento da inscrição do vestibular: "Não me identifiquei porque eu queria ser avaliado igual aos outros, como se fosse um aluno normal”.

\section{A Descoberta da SA: família e instituição de ensino superior:}

Para a família de Adam, mesmo tendo percebido as diferenças no desenvolvimento ao compará-lo com o irmão mais velho, não imaginavam que ele tinha SA, até então uma patologia totalmente desconhecida. A mãe de Adam sentia-se incomodada com o fato do filho 
não olhar nos olhos ao conversar e falar insistentemente sobre um só assunto: "Isso me incomodava muito e eu não sabia o que era" (mãe). Chegar ao diagnóstico não foi fácil, principalmente pela falta de recursos financeiros da família: "Demorava pra conseguir consulta no posto. Quando descobrimos a SA foi um susto pra nós! Depois percebemos que ele é especial e ter SA não vai atrapalhar sua vida. Mesmo ele sentindo vergonha disso, é um ótimo menino!" (mãe).

Quando esta realidade é diagnosticada surgem na família muitos questionamentos e por vezes uma sensação de fracasso que exige dos membros um período de adaptação para modificar as suas expectativas e aceitar a pessoa como diferente. Essa reação varia de uma família para a outra, em alguns casos o processo é longo e difícil, noutros é mais fácil. (POWELL; OGLE, 1991). Destaca-se que o diagnóstico deve ser feito através da observação de comportamentos, não existem exames clínicos para identificar a SA (GOMES, 2013).

No âmbito universitário, o professor de Adam relatou que o comunicado antecipado de que receberia um aluno com SA foi válido: "Me passaram o nome do aluno e eu tive a oportunidade de me preparar, não me assustar com a situação, procurar entender as peculiaridades da deficiência”. Quando os professores conhecem bem as possibilidades de aprendizagem dos alunos e os fatores que a favorecem, podem auxiliar de forma mais específica suas necessidades, principalmente quando é necessária a adaptação de material didático. De acordo com Coll (2004, p. 294) "conhecer bem os alunos implica interação e comunicação intensa com eles, uma observação constante de seus processos de aprendizagem e uma revisão da resposta educativa que lhes é oferecida".

A assistente social, por sua vez, atendeu Adam por um pedido da coordenação de curso que entrou em contato com o Núcleo de Assistência Estudantil, relatando que havia um aluno com SA. Ela comentou que Adam compareceu no dia agendado, com duas horas de antecedência: "Chegou e ficou lendo na recepção, esperando eu chamar”. Neste atendimento, conversaram sobre a deficiência, histórico familiar e escolar e adaptação à Universidade, mas Adam não ficou à vontade: "Disse que não gostava de falar no assunto, que fazia mal pra ele, mesmo sabendo que sua deficiência era leve, pois pesquisava o assunto".

\section{A Tríade: família, instituição de ensino superior e inclusão:}

Para Adam, seu ambiente familiar era harmonioso. Ele tinha um ótimo relacionamento com o irmão mais velho: "Somos muito amigos. Viemos juntos pra faculdade”. Relatou que conversam sobre diversos assuntos e buscavam fazer as refeições juntos: "Converso com 
meus pais e meu irmão, sem problema nenhum. Eles me respeitam, me ajudam quando preciso".

Os assuntos relativos a estudos sempre foram tema das conversas em família, desde o ensino fundamental: "Sempre foram interessados em saber de tudo que acontecia em minha vida e do meu irmão". A família buscava acompanhar a vida acadêmica do filho: "Mesmo não entendendo os trabalhos do Adam, perguntamos para ele como estão os estudos. A gente vê ele estudando, se dedicando. A gente percebe que isso é importante pra ele: se formar!" (pai). De acordo com os pais, quando Adam tinha dúvidas sobre algum assunto relacionado à universidade, a família conversava, mas quem auxiliava era o irmão mais velho: "A gente não tem muito estudo, por isso acabamos deixando para o irmão ajudar” (mãe). Os irmãos têm uma relação muito boa e trocam conhecimentos. Conforme Oliveira (2010), os irmãos podem se tornar os melhores aliados dos pais no cuidado de pessoas com SA. Eles também podem ser seus melhores amigos, servir como modelos e ajudá-los a compreender o mundo social. O subsistema fraterno é um contexto privilegiado para aprender a resolver conflitos. Esta modelação, fruto das relações entre iguais vai ser utilizada não só com os grupos de amigos ou na escola, como, também na vida profissional e nas relações afetivas adultas. (MINUCHIN, 1979).

O professor de Adam entendia que o grande número de alunos e poucos encontros em aula tornavam a aproximação com a família mais difícil: “Acho importante o envolvimento com a vida acadêmica do filho, mas aqui no ambiente da universidade a gente não tem informação e tem pouco contato com os familiares nos casos em que poderia ser útil”. Ele acreditava que a participação da família no processo de inclusão é importante: "Poder contar com a família no desenvolvimento deste processo e poder servir de motivação para os alunos é uma forma de tranquilizar os pais".

A assistente social também referiu não conhecer pessoalmente a família de Adam. Ela entendia ser importante a participação da família na vida acadêmica dos filhos: "Os pais poderiam não investir nele, achar que ele não é capaz, mas pelo que conversei com ele parece que ele tem esse apoio". No caso da SA, a família assume um papel relevante no tratamento, conhecendo as dificuldades implicadas e sabendo agir a fim de ajudar no desenvolvimento de habilidades. (GOMES, 2013).

Para Adam, a existência de uma equipe composta por assistente social e psicóloga na universidade era importante para atender e acompanhar as necessidades de cada aluno: "Para os alunos cadeirantes, cegos, também é importante, e para os outros alunos também”. Já os seus pais desconheciam a existência de um setor de atendimento ao aluno na universidade: 
"Não imaginava que em uma universidade existia esse tipo de serviço e nem que os pais poderiam procurar também. Afinal os alunos já são adultos” (pai), mas o avaliaram como importante: "Bom saber que se for preciso meu filho tem onde buscar ajuda e nós estamos sempre à disposição também para auxiliar" (mãe). O professor entendia que o atendimento especializado também ficava à disposição dos professores na condução de situações que ocorriam dentro da sala de aula ou no campus, mas destacava que a procura era pouca ou não acontecia: “Os professores deveriam ficar atentos e entrar em contato com o serviço ou com os familiares para ter alguma informação. Saber se tem alguma patologia ou faz algum tratamento, se está tudo bem com o aluno".

Em relação à inclusão, Adam considerava ter sido bem acolhido pela turma, professores e coordenação: "Aqui me sinto parte, acho que o processo de inclusão tem sido bem conduzido". O aluno queria concluir seu curso na área das ciências humanas: "Não quero ficar trancado em um escritório. Quero fazer pesquisas".

Os pais de Adam reconheciam a vontade do filho em estudar e a dedicação que tinha na faculdade. Entendiam que sem o apoio da família poderia ser diferente: “É muito bom para nós perceber a felicidade dele na realização de um sonho. Mesmo nem sabendo muito do curso, ver ele diariamente satisfeito é gratificante pra gente!" (mãe). O professor relatou que o desempenho acadêmico de Adam foi dentro da média da turma e sem maiores problemas: "Foi bom! Ele estava dentro das características da turma. Faz perguntas para o professor".

Adam tinha em sua família a segurança para sanar suas dúvidas, conversar sobre suas angústias e dividir suas alegrias. Ele entendia que sempre teve o apoio necessário para o processo de inclusão no ensino superior e, mesmo que não concordassem inteiramente com a escolha do curso, sempre respeitaram sua escolha: "Minha mãe diz: o que tu queres fazendo esse curso? Na verdade, eles queriam que eu seguisse o curso de Direito”. Para Gentile (2006), se a família demonstrar curiosidade em relação ao que acontece em sala de aula e reforçar a importância do que está sendo aprendido, contribuirá muito para o sucesso da aprendizagem.

\section{Desafios Sociais e Acadêmicos:}

Adam apresentava dificuldade em assumir a SA: "Não gosto de falar desse assunto! Só o professor sabe. Só contei pra ele”. Ao ser questionado se já havia passado por algum constrangimento ou preconceito por ter revelado ser Asperger, Adam relatou: "No ensino fundamental um guri disse: olha lá aquele retardadinho, quer passar de ano só porque é doente mental". Rodrigues (2012) destaca que os portadores da SA, têm consciência das suas 
diferenças, fazendo com que estes sofram e se sintam frustrados, o que não acontece com os Autistas. No ensino médio Adam conta que teve dificuldades com a troca de escola e para fazer novos amigos: "No início me senti rejeitado, muito sozinho, mas graças a uma professora que percebeu isso e me integrou, eu virei amigo dos meus colegas. Gostavam de mim! Eu me sentia querido por todos!’. Com a ajuda da professora, Adam sentiu-se incluído no grupo e reconhecido como pessoa: "Na formatura a turma me homenageou. Quando chamaram meu nome pra buscar o certificado, todos me aplaudiram de pé e eu chorei!".

Com a entrada no ensino superior, Adam sentia-se mais preparado para conviver com diferentes colegas e não encontrou dificuldades em se aproximar e fazer amizades: "Sou amigo de todo mundo!'”. A dificuldade de relacionamento social nas pessoas com SA é uma realidade, porém, quando estas são estimuladas desde cedo, conseguem se desenvolver e ajustar-se profissionalmente. (BARBIRATO; DIAS, 2009).

Os pais de Adam conseguiam perceber algumas dificuldades do filho como a caligrafia e a escrita: "Adam escreve somente com letra de forma e não usa vírgula nas frases" (mãe). Relatam também que o filho tinha dificuldades em assumir sua deficiência perante os amigos e por vezes, até perante familiares, por vergonha de ser visto como diferente: "Muitos não sabem que ele tem SA e quando contamos ficam assustados, surpresos. Adam tem medo que as pessoas pensem que ele mente pra tirar algum proveito” (pai).

Na questão da socialização, o professor de Adam relatou que: "Não é um aluno com dificuldades de relacionamento. É comunicativo e estava sempre cercado de um ou dois colegas. Não parecia com dificuldade de relacionamento”. A assistente social também indicou que Adam não apresentava dificuldades em se relacionar: "É um jovem bem falante que já participou de um processo seletivo aqui na instituição”. Ela enfatizou que o que chamou sua atenção foi o fato do aluno não olhar nos olhos quando falava: "Conversa naturalmente sobre vários assuntos, mas não te olha!'”. A psicóloga não havia atendido o aluno, pois ele não compareceu no horário agendado e não solicitou novo atendimento.

A família convivia bem com a deficiência de Adam, respeitam sua posição de não contar para as pessoas sobre a SA e deixavam o filho à vontade para conversar sobre suas necessidades. A valorização, o incentivo, a compreensão, o diálogo e a expressão de sentimentos favoreciam a melhoria na relação familiar.

\section{Sínteses dos casos cruzados:}

Os casos se assemelham pela composição familiar, pois as famílias são formadas por pai, mãe e um irmão mais velho com a mesma idade, 22 anos, sendo que todos residiam 
juntos. Para os participantes seu ambiente familiar era adequado. Max o considerava excelente e Adam o definiu como harmonioso. Eles afirmaram que conversavam com os pais sobre assuntos acadêmicos e acreditavam que essa partilha contribuía para seu desenvolvimento.

Diante disso, podemos afirmar que a maneira como os pais interagem com seus filhos é importante para o desenvolvimento social desde a infância até a fase adulta. Além disso, seus próprios comportamentos funcionavam como modelos para as atitudes dos filhos e estes tinham mais efeito na aprendizagem do que as regras estipuladas. (WEBER, 2009). Os pais de Max e Adam entendiam a importância de fazer parte da vida acadêmica dos filhos, estavam satisfeitos com a condução do processo de inclusão no ensino superior e percebiam que a influência da família estava ligada ao modo como seus filhos se inseriram e como pensavam concluir a graduação.

Nos dois casos, os alunos iniciaram um curso e trocaram no decorrer do ano. Max trocou devido a um desentendimento com a coordenação, e Adam por não ter se identificado com o curso. Eles escolheram o curso atual por afinidades pessoais e consideravam que tinham sido bem recebidos pela coordenação de curso, além de terem tido o apoio da família para seguir estudando. O apoio recebido da família proporcionava maior motivação, facilitando a aprendizagem de cada habilidade e permitindo mais acertos do que erros, já que os aspergers costumam ter baixa resistência à frustração. (CAMARGOS et al., 2013).

Para os professores dos participantes era a primeira experiência com alunos com SA. De acordo com eles, os dois apresentavam bom desempenho acadêmico, eram questionadores em sala de aula e tinham bom relacionamento com os colegas de turma. Para ambos a participação da família era importante e influenciava no desempenho acadêmico.

A assistente social e a psicóloga da IES, por sua vez, atenderam o participante Max em horários distintos, mas pelo mesmo motivo, conflito com professor. Ambas conheciam a família de Max e a consideravam participativa, mas, ao mesmo tempo, exigente. Elas entendiam que a socialização de Max era afetada pelos sintomas da SA, devido a sua fala ser formal e robótica, o que dificultava a comunicação com os colegas. Já Adam foi atendido pela assistente social devido a uma solicitação da coordenação de curso, mas no atendimento agendado com a psicóloga ele não compareceu. Ambas não conheciam a família de Adam.

Cabe também destacar como os casos se diferenciavam. Inicialmente, pontua-se a idade em que foi diagnosticada a SA. Max foi diagnosticado aos 5 anos e fazia acompanhamento psicológico desde então. Já Adam teve a confirmação do diagnóstico somente com 10 anos e nunca fez acompanhamento. 
O participante Max estudou em escola privada e teve material pedagógico adaptado. Ele não sentia vergonha de seu diagnóstico e se identificou no vestibular como pessoa com SA, considerando-se especial. Adam estudou em escola pública e não teve material pedagógico adaptado em nenhuma situação. Ele não se identificou como pessoa com SA, pois não queria ser tratado de forma diferente e sentia vergonha do diagnóstico, não gostando de falar sobre o assunto.

Quanto à família, perceberam-se particularidades em relação à escolaridade dos pais. Os pais de Max tinham ensino superior completo enquanto que os de Adam somente concluíram o ensino médio. A mãe de Max era profissional liberal e contava com a ajuda de uma empregada doméstica para a organização da casa. Já a mãe de Adam parou de trabalhar depois do casamento e dedicou-se a criação dos filhos e cuidados domésticos. Na família de Max, somente seus pais trabalhavam e eram responsáveis pelo sustento de todos; na família de Adam, além de seu pai, seu irmão também trabalhava e ajudava nas despesas da casa. Adam estava em busca de estágio com o mesmo objetivo.

Os pais de Max foram contatados pela universidade e conheceram o serviço especializado da IES, além de também terem conversado com a coordenação de curso para obterem esclarecimentos sobre a formação do filho. No caso de Adam, seus pais nunca foram à universidade e desconheciam a existência do setor.

Embora a satisfação em ter os filhos cursando a universidade esteja presente na fala das duas famílias, a conclusão do ensino superior para os pais de Max tinha como objetivo uma boa colocação no mercado de trabalho, enquanto que os pais de Adam entendiam que o filho iria realizar um sonho pessoal. Nos casos estudados, foi possível constatar características marcantes das famílias que perpassaram para os filhos. Em Max a formalidade era perceptível já nos primeiros contatos, enquanto que em Adam a afetividade era a característica predominante.

Quanto ao processo de aprendizagem, a família de Max ressaltou prejuízos na linguagem e na comunicação, já a família de Adam considerava a escrita como uma dificuldade. A professora de Max percebia que o aluno tinha dificuldades de falar em público, mas não apresentava problemas de relacionamento com a turma. Já o professor de Adam considerava o aluno comunicativo e com bom relacionamento com a turma.

O serviço de apoio especializado da IES pareceu ser parte fundamental no processo de inclusão, pois possibilitou a aproximação com a família, permitindo melhor entendimento das características de cada aluno, para uma melhor aprendizagem e vivência acadêmica. Outra questão importante parece ser o professor, pois ao realizar as mediações necessárias, através 
de instrumentos de ensino e práticas pedagógicas adequadas, propiciava o processo de inclusão de forma heterogênea no grupo. Através deste estudo percebeu-se que para todos os participantes, a família influencia no processo de inclusão, e o afeto entre pais e filhos, a busca pelo desenvolvimento e superação de Max e Adam foi presente nas falas.

\begin{tabular}{|c|c|c|}
\hline Semelhanças & $\operatorname{Max}$ & Adam \\
\hline $\begin{array}{l}\text { A descoberta da SA: família e } \\
\text { instituição de ensino superior }\end{array}$ & $\begin{array}{l}\text { Primeira experiência para a } \\
\text { professora }\end{array}$ & $\begin{array}{l}\text { Primeira experiência para o } \\
\text { professor }\end{array}$ \\
\hline $\begin{array}{l}\text { A tríade: família, instituição de } \\
\text { ensino superior e inclusão }\end{array}$ & Família satisfeita com o filho na IES & $\begin{array}{l}\text { Família satisfeita com o filho } \\
\text { na IES }\end{array}$ \\
\hline Desafios sociais e acadêmicos & $\begin{array}{l}\text { Trocou de curso } \\
\text { Pais percebiam dificuldades no filho: } \\
\text { linguagem e comunicação }\end{array}$ & $\begin{array}{l}\text { Trocou de curso } \\
\text { Pais percebiam dificuldade no } \\
\text { filho: escrita }\end{array}$ \\
\hline Particularidades & Max & Adam \\
\hline $\begin{array}{l}\text { A descoberta da SA: família e } \\
\text { instituição de ensino superior }\end{array}$ & $\begin{array}{l}\text { Idade do diagnóstico: } 5 \text { anos } \\
\text { Faz acompanhamento psicológico } \\
\text { Não sente vergonha por ter SA } \\
\text { Identificou-se com SA no vestibular }\end{array}$ & $\begin{array}{l}\text { Idade do diagnóstico: } 10 \text { anos } \\
\text { Não faz acompanhamento } \\
\text { Sente vergonha por ter SA } \\
\text { Não se identificou com SA no } \\
\text { vestibular }\end{array}$ \\
\hline $\begin{array}{l}\text { A tríade: família, instituição de } \\
\text { ensino superior e inclusão }\end{array}$ & $\begin{array}{l}\text { Família conhece o serviço } \\
\text { especializado da IES } \\
\text { Relação fraterna distante }\end{array}$ & $\begin{array}{l}\text { Família não conhece o serviço } \\
\text { especializado da IES } \\
\text { Relação fraterna próxima }\end{array}$ \\
\hline Desafios sociais e acadêmicos & $\begin{array}{l}\text { A família já tinha tido atendimento } \\
\text { com serviço especializado da IES } \\
\text { Não gostava de falar em público } \\
\text { Estudou em escola privada com } \\
\text { material adaptado }\end{array}$ & $\begin{array}{l}\text { Família não conhecia o serviço } \\
\text { especializado da IES } \\
\text { Era comunicativo } \\
\text { Estudou em escola pública sem } \\
\text { material adaptado }\end{array}$ \\
\hline
\end{tabular}

\section{Quadro 1 - Semelhanças e Particularidades entre os Casos Fonte: Elaborado pela autora.}

\section{Considerações finais:}

Frente ao exposto, constatou-se que a relação instituição de ensino-família existe, embora ainda seja preciso incentivá-la, o que, em geral, ocorre por parte da IES que oferece acompanhamento de uma assistente social e de uma psicóloga na busca pela inclusão plena do aluno com SA no meio acadêmico, respeitando suas necessidades e oferecendo um espaço para acolhimento de suas demandas, assim como as de sua família. Porém, para que o trabalho em conjunto aconteça, a divulgação do serviço deve ser feita de forma mais efetiva, tanto para os alunos como para as suas famílias e os professores da instituição.

Mesmo que tenha se verificado a participação das famílias no processo de inclusão dos filhos adultos investigados, seus objetivos eram diferentes. Enquanto a família de Max se 
preocupava com o status que a conclusão da graduação poderia trazer, a família de Adam se referia à realização pessoal do filho, o que pode estar associado à condição econômica e social de cada uma delas. As relações fraternas também se apresentaram de forma diferente, pois Max se referiu ao irmão apenas quando questionado sobre com quem morava, já Adam revelou a figura do irmão bem presente na sua rotina e uma relação de companheirismos reafirmada pela fala dos pais.

Em relação aos professores, a necessidade de qualificação referente ao tema da inclusão do aluno com SA ficou evidente. Nos dois casos, os professores afirmaram ser necessária a discussão do tema, pois alguns colegas se negavam a pedir ajuda por não quererem assumir suas limitações.

Pode-se afirmar que a produção sobre a inclusão no ensino superior ainda é escassa diante de sua importância, visto que os estudos atuais são, em sua maioria, referentes à inclusão de crianças. Portanto, acredita-se que este estudo possibilitou um maior entendimento sobre a inclusão do adulto com SA no ensino superior na perspectiva do aluno, sua família, seus professores, a assistente social e a psicóloga instituição de ensino, bem como sobre a influência da família neste processo. Sugere-se que estudos posteriores investiguem a inclusão de alunos adultos com outros diagnósticos, para identificar as diferenças e peculiaridades de cada caso no que tange a deficiências físicas e intelectuais distintas. Também seria interessante a realização de estudos longitudinais que acompanhassem alunos de inclusão desde o início de sua formação acadêmica até sua inclusão no mercado de trabalho.

\title{
INCLUSION PROCESS OF ADULTS WITH ASPERGER SYNDROME' AT HIGHER EDUCATION
}

\begin{abstract}
:
This article is subject to inclusion of adult students with Asperger Syndrome (SA) in higher education. The objective, sought to understand the process of inclusion adults with SA in a higher education institution (HEI) from the perspective of the student and his family, as well as teachers, social worker and psychologist at the IES. Family and socio-economic context of these students and their relationship and your family with professional IES was characterized. We conducted a study of exploratory and transversal, with delineation of multiple case studies. Participated in two adults with SA, male, aged between 18 and 20 years, enrolled in a private institution, located in the metropolitan region of Porto Alegre -RS, as well as parents, teachers, social worker and psychologist at the HEI. Like a collection instrument we used semi-structured interviews. The qualitative content analysis, from the method of theoretical propositions, revealed that the prospect of completion of higher education has different meanings for families and that its relation with the HEI, although it exists, needs to be encouraged. Also noted the need for qualification of teachers regarding the inclusion. It is
\end{abstract}


believed that this study allowed for a better understanding of the inclusion of the adult with SA through the eyes of those involved in this process.

Keywords: Inclusion. Asperger Syndrome. Family-university relationship.

\section{PROCESO DE INCLUSIÓN DEL ADULTO CON SÍNDROME DE ASPERGER EN LA EDUCACIÓN SUPERIOR}

\section{Resumen:}

El presente artículo tiene como tema la inclusión de los estudiantes adultos con Síndrome de Asperger (SA) la educación superior. Este estudio tiene como objetivo comprender el proceso de inclusión de los adultos con SA en una institución de educación superior (IES) desde la perspectiva del estudiante y su familia, maestros, trabajador social y psicólogo de la IES. Con este fin, se caracterizó el entorno familiar y socioeconómico de los estudiantes, su relación y de su familia con los profesionales del IES. Se realizó un estudio de carácter exploratorio y transversal, con delineamiento de estudios de casos múltiples. Asistió a dos adultos con SA, del sexo masculino, con edades compreendidas entre 18 e 20 años, matriculados en una institución privada, situada en la región metropolitana de Porto Alegre-RS, así como los padres, los maestros, trabajador social y psicólogos de la IES. Como instrumento de recolección de datos se utilizaron de entrevistas semi-estructuradas. Lá análisis de contenido cualitativo reveló que la perspectiva de la finalización de la educación superior tienem diferentes significados para las familias y que su relación con la IES, aunque exista, necesita ser alentalo. También señaló la necesidad de capacitación de los maestros con respecto a la inclusión. Se cree que este estudio permitió una mejor comprensión de la inclusión de los adultos con SA a través de los ojos de los que participan en este proceso.

Palabras clave: Inclusión. Síndrome de Asperger. Relación familia-universidad.

\section{Referências:}

ALVES, M. Aconselhamento parental na Síndrome de Asperger. Revista Diversidades, Medeira, PT, n. 26, p. 4-8. 2009.

ANDOLFI, M. A Terapia Familiar. Lisboa, Editorial Veja, 1981.

AMERICAN PSYCHIATRIC ASSOCIATION (APA). DSM V. Manual Diagnóstico e Estatístico de Transtornos Mentais. Tradução de D. Batista. 5. ed. Porto Alegre: Artes Médica, 2013.

AMORIM, L.C.D.; ASSUNÇÃO JR, F. B. O conceito de morte e a Síndrome de Asperger. Rev. Estudos de Psicologia, Ano XXIX - n. 3, p. 363-370, Campinas, Jul. /Set. 2012. Disponível em: $<$ http://www.scielo.br/readcube/epdf.php?doi=10.1590/S0103-166X2012000300006\&pid=S0103166X2012000300006\&pdf_path=estpsi/v29n3/06.pdf\&lang=pt> Acesso em 18 out 2017.

ATTWOOD, T. "Precisamos de pessoas com Asperger". [5 jun. 2009]. Entrevistadora: Elsa Páscoa. Pais \& Filhos, Porto, PT, 5 jun. 2009. Disponível em:

$<$ http://www.paisefilhos.pt/index.php/component/content/1503?task=view\&limit=1\&showall=1>

Barbarói, Santa Cruz do Sul, n.49, p.<258-285>,jan./jun. 2017 
Acesso em: 02 set. 2014. Entrevista concedida a Pais \& Filhos.

A Síndrome de Asperger: um guia para pais e profissionais. Lisboa: Verbo, 2006.

The Complete Guide to Aspergers Sindrome. London: Philadelphia: Jessica Kinsley Publishers. 2008.

BARBIRATO F., DIAS G. A Mente do seu Filho: como estimular as crianças e identificar os distúrbios psicológicos na infância. Rio de Janeiro: Agir; 2009.

BORREGUERO, P. El Síndrome de Asperger: excentricidad o discapacidad social? 6. ed. Madrid: Alianza, 2006.

BRASIL. Constituição. Constituição da República Federativa do Brasil. Brasília: Senado Federal, 1988.

Decreto Legislativo $\mathrm{n}^{\circ} \mathbf{1 8 6}$, de 9 de julho de 2008. Aprova o texto da Convenção sobre os Direitos das Pessoas com Deficiência e de seu Protocolo Facultativo, assinados em Nova Iorque, em 30 de março de 2007. Brasília, 9 de julho de 2008. Disponível em: <http://www.planalto.gov.br/ccivil_03/constituicao/ Congresso/DLG/DLG-186-2008.htm> Acesso em: 08 out. 2013.

Decreto $n^{0}$ 5.296, de 2 de dezembro de 2004. Regulamenta as Leis nos 10.048, de 8 de novembro de 2000, que dá prioridade de atendimento às pessoas que especifica, e 10.098, de 19 de dezembro de 2000, que estabelece normas gerais e critérios básicos para a promoção da acessibilidade das pessoas portadoras de deficiência ou com mobilidade reduzida, e dá outras providências. Brasília, DF 2 dez. 2004. Disponível em: <http://www.planalto.gov.br/ccivil_03/_ato2004-2006/2004/decreto/d5296.htm> Acesso em: 10 out. 2013.

Decreto $\mathrm{n}^{\mathbf{0}}$ 5.626, de 22 de dezembro de 2005. Regulamenta a Lei no 10.436, de 24 de abril de 2002, que dispõe sobre a Língua Brasileira de Sinais - Libras, e o art. 18 da Lei no 10.098, de 19 de dezembro de 2000. Brasília, 22 de dezembro de 2000. Disponível em: <http://www.planalto.gov.br/ccivil_03/_ato2004-2006/2005/decreto/d5626.htm> Acesso em: 10 out. 2013.

Decreto $\mathbf{n}^{0}$ 6.949, de 25 de agosto de 2009. Promulga a Convenção Internacional sobre os Direitos das Pessoas com Deficiência e seu Protocolo Facultativo, assinados em Nova York, em 30 de março de 2007. Brasília, DF, 25 ago. 2009. Disponível em: <http://www.planalto.gov.br/ccivil_03/_ato2007-2010/2009/decreto/d6949.htm> Acesso em: 08 out. 2013.

Decreto $\mathbf{n}^{0}$ 7.611, de 17 de novembro de 2011. Dispõe sobre a educação especial, o atendimento educacional especializado e dá outras providências. Brasília, DF, 17 nov. 2011. Disponível em: <http://www.planalto.gov.br/ccivil_03/_Ato 2011-2014/2011/Decreto/D7611.htm> Acesso em: 10 out. 2013.

Estatuto da Pessoa com Deficiência. Brasília, DF: Senado Federal, 2015.

Lei de Diretrizes e Bases da Educação Nacional. LDB 9.394. Brasília, DF, 1996. Disponível em: <http://www.planalto.gov.br/ccivil_03/leis/19394.htm> Acesso em: 8 out. 2013. 
. Ministério da Educação, Lei de Diretrizes e Bases da Educação Nacional. LDB 4.024. Brasília, DF, 1961. Disponível em: < http://www.planalto.gov.br/ccivil_03/leis/L4024.htm> Acesso em: 18 out. 2017.

BRASIL. Ministério da Educação. Secretaria de Educação Especial. Política Nacional de Educação Especial. Brasília, DF: MEC/SEESP, 1994.

Ministério da Educação. Secretaria de Educação Especial. Parâmetros Curriculares Nacionais. Adaptações curriculares. Estratégias para a educação de alunos com necessidades especiais. Brasília, DF: MEC / SEF / SEESP, 1999.

. Ministério da Educação. Diretrizes Nacionais para a Educação Especial na Educação Básica/Secretaria de Educação Especial. Brasília, DF: MEC/SEESP, 2001.

Ministério da Educação. Secretaria de Educação Especial. Política Nacional de Educação Especial na Perspectiva da Educação Inclusiva. Brasília, DF: MEC/SEESP, 2008. Disponível em: <http://portal.mec.gov.br/arquivos/pdf/ politicaeducespecial.pdf> Acesso em: 11 out. 2013.

. Ministério do Trabalho e Emprego. Classificação Brasileira de Ocupações. Brasília, DF, 2002. Disponível em: <http://www.mtecbo.gov.br/cbosite/pages/home.jsf> Acesso em: 8 out. 2013.

Secretaria Especial dos Direitos Humanos. Coordenadoria Nacional para Integração da Pessoa Portadora de Deficiência - CORDE. Convenção sobre os direitos das pessoas com deficiência. Brasília, DF, set. 2007.

BZUNECK, J. A. A motivação do aluno: aspectos Introdutórios. In: BORUCHOVITCH, E.; BZUNECK, J. A. (Orgs.). A Motivação do Aluno: contribuições da psicologia contemporânea. Petrópolis, RJ: Vozes, 2001.

CAMARGOS Jr., W. e COLS. Síndrome de Asperger e Outros Transtornos do Autismo de Alto Funcionamento: da avaliação ao tratamento. Belo Horizonte: Arte Sã, 2013.

CANADA. Declaração de Montreal sobre Deficiência Intelectual. Montreal, 6 out. 2004. Disponível em: <http://www.defnet.org.br/decl_montreal.htm> Acesso em: 10 out. 2013.

CARTER, B.; McGOLDRICK, M. As Mudanças no Ciclo de Vida Familiar: uma estrutura para a terapia familiar. 2. ed. Porto Alegre: Artes Médicas, 1995. p. 7-29.

COLL, C., MARCHESI, J. e PALACIOS, A. Desenvolvimento Psicológico e Educação: transtornos de desenvolvimento e necessidades educativas especiais. 2. ed. Porto Alegre: Artmed, 2004.

DANTAS, B.L.F.C.; ALCHIERI, J.C.; Síndorme de Asperger: um estudio de caso. XIII Congresso Virtual de Psiquiatria, INTERPSIQUIS. Fev. 2012.. Disponível em: <http://www.psiquiatria.com/bibliopsiquis/handle/10401/5143>Acesso em: 17 out.2017 
DANTAS, D. C. L. A Inclusão de Pessoas com Deficiência Intelectual na Educação de Jovens e Adultos - EJA: um estudo de caso. 2012. Tese (Doutorado) - Centro de Educação, Programa de Pós-Graduação em Educação, Universidade Federal do Rio Grande do Norte, Natal, 2012.

DESSEN, M. A.; LEWIS, C. Como estudar a "família" e o "pai"? Paidéia: cadernos de psicologia e educação, Ribeirão Preto, v. 8, n. 14-15, p. 105-121, fev./ago. 1998.

DESSEN, M.A.; POLONIA, A. C. A família e a escola como contextos de desenvolvimento humano. Paidéia: cadernos de Psicologia e Educação, Ribeirão Preto, v. 17, n. 36, 21-32. 2007.

FÁVERO, M. A. B.. Trajetória e Sobrecarga Emocional da Família de Crianças Autistas: relatos maternos. 2005. 175 f. Dissertação (Mestrado em Ciências) - Universidade de São Paulo, São Paulo, 2005.

FERRARI, M.; KALOUSTIAN, S. M. Introdução - Família Brasileira: a base de tudo. 6. ed. São Paulo: Cortez; Brasília, DF, Unicef, 2004.

FONSECA, V. Introdução às Dificuldades de Aprendizagem. 2. ed. rev. aum. Porto Alegre: Artes Médicas, 1995.

GENTILE, P. Parceiros na aprendizagem. Nova Escola, São Paulo, ed. 193, jun. 2006. Disponível em: <http://revistaescola.abril.com.br/formacao/parceiros-aprendizagem-423371.shtml> Acesso em: 01 jul. 2014.

GOMES, M. C. C. Envolvimento Familiar e Autonomia na Criança com Síndrome de Asperger. Escola Superior de Educação de Paula Frasineti - Departamento de Educação Especial, Pós-Graduação em Educação Especial - Domínio Cognitivo e Motor, Porto, PT, 2013. Disponível $<$ http://repositorio.esepf.pt/bitstream/handle/123456789/1257/PG-EE_2013CarmoGomes. pdf? sequence $=1>$ Acesso em: 19 out. 2017.

INSTITUTO BRASILEIRO DE GEOGRAFIA E ESTATÍSTICA (IBGE). 7 a 12. Vamos conhecer o Brasil. Rio de Janeiro, 2011. Disponível em: <http://7a12.ibge.gov.br/ vamos-conhecero-brasil/nosso-povo/caracteristicas-da-populacao> Acesso em: 23 out. 2013.

INSTITUTO BRASILEIRO DE GEOGRAFIA E ESTATÍSTICA (IBGE). Pesquisa Nacional de saúde - PNS. Rio de Janeiro, 2013. Disponível em: < https://www.ibge.gov.br/estatisticasnovoportal/sociais/saude/9160-pesquisa-nacional-de-saude.html?\&t=resultados $>$ Acesso em: 23 out. 2013.

INSTITUTO NACIONAL DE ESTUDOS E PESQUISAS EDUCACIONAIS ANÍSIO TEIXEIRA (INEP). Censo da Educação Superior, 2011. Disponível em:

<http://portal.inep.gov.br/web/censo-da-educacao-superior> Acesso em: 01 jul. 2014.

MINUCHIN, S. Families en Thérapie. Paris, J.P. Delarge, 1979.

MOORE, S. T. Síndrome de Asperger e a Escola Fundamental: soluções práticas para dificuldades acadêmicas e sociais. São Paulo: Associação Mais 1, 2005.

NIELSEN, L. B. Necessidades Educativas Especiais na Sala de Aula: um guia para professores. Porto/Lisboa: Porto Editora, 1999. 
OLIVEIRA, M. K. Vygotsky: aprendizado e desenvolvimento: um processo sócio histórico. 5. ed. São Paulo: Scipione, 2010.

ORGANIZAÇÃO MUNDIAL DA SAÚDE (OMS). CID-10. Tradução do Centro Colaborador da OMS para a Classificação de Doenças em Português. 8. ed. São Paulo: Editora da Universidade de São Paulo, 2000.

PADILHA, A. M. L. Práticas Pedagógicas na Educação Especial: a capacidade de significar o mundo e a inserção cultural do deficiente mental. Campinas: Autores Associados, 2004.

PIAUILINO, J. D. Educando Pessoas com Autismo para Conviver em Sociedade. Araguaína: Santa Rita, 2008.

POWELL, T.; OGLE, P. El Niño Especial: el papel de los hermanos en su educación. Barcelona: Norma, 1991.

RODRIGUES, D. A Inclusão na Universidade: limites e possibilidades da construção de uma universidade inclusiva. Cadernos de Educação Especial, Santa Maria, n. 23, 2004.

RODRIGUES, M. C.A. As Atitudes dos Professores do $1^{\circ}, 2^{\circ}$ e $3^{\circ}$ Ciclos do Ensino Básico Face à Inclusão de Alunos com a Síndrome de Asperger no Ensino Regular. Dissertação (Mestrado em Ciências da Educação na Especialização em Domínio Cognitivo-Motor) - Escola Superior de Educação João de Deus, Lisboa, set. 2012. Disponível em: <http://comum.rcaap.pt/handle/ 123456789/2569> Acesso em: 02 jun. 2014.

VITAL, I. L. V. Aspectos familiares de pessoas com deficiência. In: MAGALHÃES, R. C. B. P.; LAGE, A. M. V. (Org.). Reflexões sobre a Diferença: uma introdução à educação especial. 2. ed., rev. Fortaleza: Edições Demócrito Rocha, 2003.

WEBER, L. Eduque com Carinho: equilíbrio entre amor e limites - para pais. Curitiba: Juruá, 2009.

WEISS, M. L. L. Psicopedagogia Clínica: uma visão diagnóstica dos problemas de aprendizagem escolar. 10. ed. Rio de Janeiro: DP\&A, 2004.

WILliAMS, C.; WRIGHT, B. Convivendo com Autismo e Síndrome de Asperger: estratégias práticas para pais e profissionais. São Paulo: M.Books do Brasil, 2008.

WING, L. F. In: ATTWOOD, Tony. Asperger Sindrome: a Guide for Parents and Professionals. London: Philadelphia: Jessica Kinsley Publishers. 2003.

YIN, Robert. K. Estudo de Caso: planejamento e métodos. 3. ed. Porto Alegre: Bookman, 2005.

ZAGO, N. Processos de escolarização nos meios populares: as contradições da obrigatoriedade escolar. In: NOGUEIRA, M. A.; ROMANELLI, G. (Org.). Família e Escola: trajetórias de escolarização em camadas médias e populares. Petrópolis: Vozes, 2000. p. 17-43.

ZARANZA, N. I. C. Autismo e Família: estudo dos aspectos familiares e sociais. 2008. 161 f. Dissertação (Mestrado) - Universidade Católica de Brasília, Brasília, 2008. 
Data de recebimento: 22/07/2015.

Data de aceite: 01/11/2017.

\section{Sobre as autoras:}

Angélica da Costa é Assistente social da Universidade do Vale do Rio dos Sinos (Unisinos) e especialista em Terapia de Casal e Família pela mesma instituição. Endereço para correspondência: Rua Manoel Serafim, 792. Bloco J - apto 103. Sapucaia do Sul. CEP: 930220-250. Endereço Eletrônico: angelcosta@unisinos.br

Angela Helena Marin é Doutora em Psicologia e professora dos cursos de graduação e pósgraduação em Psicologia da Universidade do Vale do Rio dos Sinos. Endereço Eletrônico: angelahm@unisinos.br 